\title{
OBTAINING OF FERROSILICOCHROMIUM POWDER ALLOY BY SILICOTHERMIC REDUCTION AND STUDY OF THE MECHANISM OF THIS PROCESS
}

\author{
V. H. Martirosyan ${ }^{1}$, M. E. Sasuntsyan ${ }^{1}$, V. V. Savich ${ }^{2}$ \\ ${ }^{I}$ National Polytechnic University of Armenia, Yerevan, Armenia \\ ${ }^{2}$ National Academy of Sciences of Belarus, Institute of Powder Metallurgy, Minsk, Belarus
}

DOI: https://doi.org/10.31435/rsglobal_wos/31012019/6307

\author{
ARTICLE INFO \\ Received: 16 November 2018 \\ Accepted: 19 January 2019 \\ Published: 31 January 2019

\section{KEYWORDS} \\ chromite concentrate, \\ metallurgical waste, \\ ferrosilicochrome, \\ powder alloy, \\ silicothermic reduction, \\ combustion wave, \\ temperature profile.
}

\begin{abstract}
The process of obtaining a powder ferrosilicochromic alloy by the method of silicothermic reduction of local chromites and slags of copper smelters was investigated. The mechanism of this process has been studied. It is established that the best results are obtained in the case of slag / chromite ratio $=1: 1$, when an alloy with microdispersed structure and high strength is obtained. The optimum composition of the resulting alloy is as follows: $35,1 \% \mathrm{Fe} ; 36,35 \% \mathrm{Si}$ and $28,53 \% \mathrm{Cr}$, with a metal yield of $98,4 \%$. The obtained alloy powder can be used as an acidified and alloying additive to chromium- and silicon-containing stainless composite materials. The aspects of the process for obtaining $\mathrm{FeSiCr}$ alloy have been developed. The maximum temperature $(\mathrm{Tc})$ and the linear propagation velocity of the combustion wave (Uv) are determined graphically. The mechanism of the formation of $\mathrm{FeSiCr}$ in the SHS process is explained.
\end{abstract}

Citation: V. H. Martirosyan, M. E. Sasuntsyan, V. V. Savich. (2019) Obtaining of Ferrosilicochromium Powder Alloy by Silicothermic Reduction and Study of the Mechanism of This Process. International Academy Journal Web of Scholar. 1(31), Vol.1. doi: 10.31435/rsglobal_wos/31012019/6307

Copyright: (C) 2019 V. H. Martirosyan, M. E. Sasuntsyan, V. V. Savich. This is an open-access article distributed under the terms of the Creative Commons Attribution License (CC BY). The use, distribution or reproduction in other forums is permitted, provided the original author(s) or licensor are credited and that the original publication in this journal is cited, in accordance with accepted academic practice. No use, distribution or reproduction is permitted which does not comply with these terms.

1. Introduction. Armenia has a powerful mien base for organizing the production of chromecontaining ferroalloys and silicium from the local raw materials $[1]$. As a chromite-containing raw material the local chromites can be used. In recent years, finding new chromite mine in Tapasar of the Sevan region with a $43 \ldots 46 \% \mathrm{Cr}_{2} \mathrm{O}_{3}$ content aroused a great interest [2-4]. But this deposit has not yet found industrial applications because of the absence of processing technologies. These ores, after enrichment can serve as a chromite-containing raw materials [5-8]. On the other hand, metallurgical waste products from Alaverdi copper smelting factory in which the content of Fe reaches 38,35\%, and the content of Si reaches $30,11 \%$ can serve as iron- and silicium- containing raw materials. Taking into consideration the fact that there is a large amount of this waste connected with the development of metallurgy of non-ferrous metals, and the high content of iron and silicium in these wastes, it becomes quite urgent to obtain ferrosilicochromium from these wastes and local chromites by new, advanced and efficient technologies. The obtained ferrosilicochromium can serve as alloying additives for obtaining ferrous chrome, as well as chrome and silicium containing valuable steels [9-12]. To obtain ferrosilicachromium by traditional technologies from appropriate metals is expensive, since metallic chrome is obtained by multiphase, complicated and labourconsuming technology [9-13]. The process of obtaining ferrosilicochromium combined with local chromites and waste products is studied by the out-of-furnace silicothermic reduction method. Now the economically effective and advanced method for obtaining alloys is the silicothermal method, which does not require great power consumption as it does at exothermic reduction reaction. It allows to provide the out-of furnace process which is the prevailing factor for the given technology [7, 8, 13]. Obtaining valuable ferrosilicochromium by alloying additives from local chromites and secondary raw material by an advanced and efficient technology characterizes the importance of the presented work. 
2. Experimental investigations. Investigations are carried out on the chromite concentrate from Tapasar. The average chemical composition of the concentrate is as follows: $\mathrm{Cr}_{2} \mathrm{O}_{3}-52,68 \%$; $\mathrm{FeO}_{\text {total }}-13,64 \% ; \mathrm{Al}_{2} \mathrm{O}_{3}-5,88 \% ; \mathrm{MgO}-20,38 \% ; \mathrm{SiO}_{2}-5,06 \% ; \mathrm{CaO}-2.36 \%$; and $\mathrm{Cr}_{2} \mathrm{O}_{3} / \mathrm{FeO}_{\text {total }}=$ 3,$86 ; \mathrm{MgO} / \mathrm{Al}_{2} \mathrm{O}_{3}=3,47$.

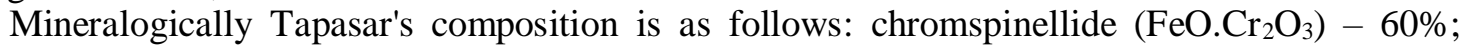
magniochromite $\left(\mathrm{FeO} . \mathrm{Cr}_{2} \mathrm{O}_{3}\right)-18 \%$; magnetite $\left(\mathrm{Fe}_{3} \mathrm{O}_{4}\right)-5 \%$; serpentine $\left(\mathrm{mSiO}_{2} \mathrm{nAl}_{2} \mathrm{O}_{3}\right)-17 \%$. As can be seen the concentrate is mainly composed of chromespinellide and magniochromite. Magnetite occurs in a free form [14].

In the Alaverdi copper smeltery, the iron- and silicium- containing material produces metallurgical waste products from in which the content of Fe reaches $38,35 \%$ and the content of Si reaches 30,11\%.

$\mathrm{X}$-ray diffraction (XRD) examination with monochromatic $\lambda \mathrm{CuK} \alpha$ radiation (DRON-3 diffractometer) was performed. A scanning electron microscope (SEM) VEGA TS 5130MM, Tescan, Czech Republic, Microanalysis System INCA Energy 300, Oxford Instruments, UK7 and Energy Dispersive X-ray microanalyses were used for metallographic investigations [15-19].

3. Results and discussion. The main purpose of the work is the investigation of the ferrosilicachromium obtaining process by joint silicathermic reduction of the Tapasar (Armenia) chromites $\left(48 \% \mathrm{Cr}_{2} \mathrm{O}_{3}\right)$ and tail slags of the Alaverdi copper factory.

The great amount of heat released at the silicathermic reduction of chromium, iron and silicon oxides contained in chromites and tail slags is the reason for self-propagating high-temperature synthesis (SHS), realized as a combustion wave propagating through the sample of initial mixture raising the temperature in the system up to $2500-3000 \mathrm{~K}[7,8]$. As a result of reduction of chromium, iron, and silicon oxides, a metallic phase is formed, and a mixture of oxides forms a slag containing mainly silicates and aluminosilicates.

The work is devoted to obtaining a Fe-Si-Cr alloy of the following composition: $36-38 \% \mathrm{Fe}$; $28-30 \% \mathrm{Cr} ; 35-40 \% \mathrm{Si}$. This ferrosilicochromium alloy is applied in the industry as an acidifying and alloying additive to the chromium- and silicon-containing stainless steels.

For obtaining the alloy, a charge was prepared containing chromite, tail slags, reducers (Fe-Si and aluminum powder), as well as $\mathrm{CaO}$ and $\mathrm{NaNO}_{3} . \mathrm{NaNO}_{3}$ is added to the initial mixture as an agent for increasing the reduction temperature, and $\mathrm{CaO}$ is used as an additive which forms a melt and integrates oxides in the charge.

The experiments were performed as follows [7,8]. A green mixture prepared from initial reactants of certain proportions was homogenized and placed in a container filled with sand. The $\mathrm{Ti}+\mathrm{C}$ mixture was used as an igniter. The combustion was initiated by means of an incandescent wire. The duration of the experiment was 12-15 min. Under these conditions, a metallic alloy and a slag phase were formed which were easily separated after cooling. Both phases were weighted. The metallic phase was examined by chemical, X-ray and microscopic analyses.

In the work, first the yield of the metal, depending on the chromite and the tail slag ratio is studied. Below are introduced the results of that investigation (Fig. 1 a,b,c; 2 a,b,c; 3a).

Fig. 1a shows the microscopic view of the metal mass in the case of the dump slag/chromite ratio 0,5:1. As it can be seen from the figure, the obtained metallic phase is microdisperse to some extent and relatively strong. Here, the degree of the metal outcome is also high $(79,8 \%)$. According to the data of the chemical analysis, the composition of the alloy is as follows: $\mathrm{Fe}-32 \%, \mathrm{Si}-40 \%$, and $\mathrm{Cr}-28 \%$.

The next figure introduces the dump slag/chromite ratio 1:1 (Fig. 1b). In this picture, the metallic phase is the most microdisperse and uniform, and the obtained alloy is more aggregate and stronger externally. The degree of metal extraction here is $88 \%$. According to the data of the chemical analysis, the composition of the alloy is as follows: $\mathrm{Fe}-40 \%, \mathrm{Si}-34 \%$, and $\mathrm{Cr}-26 \%$.
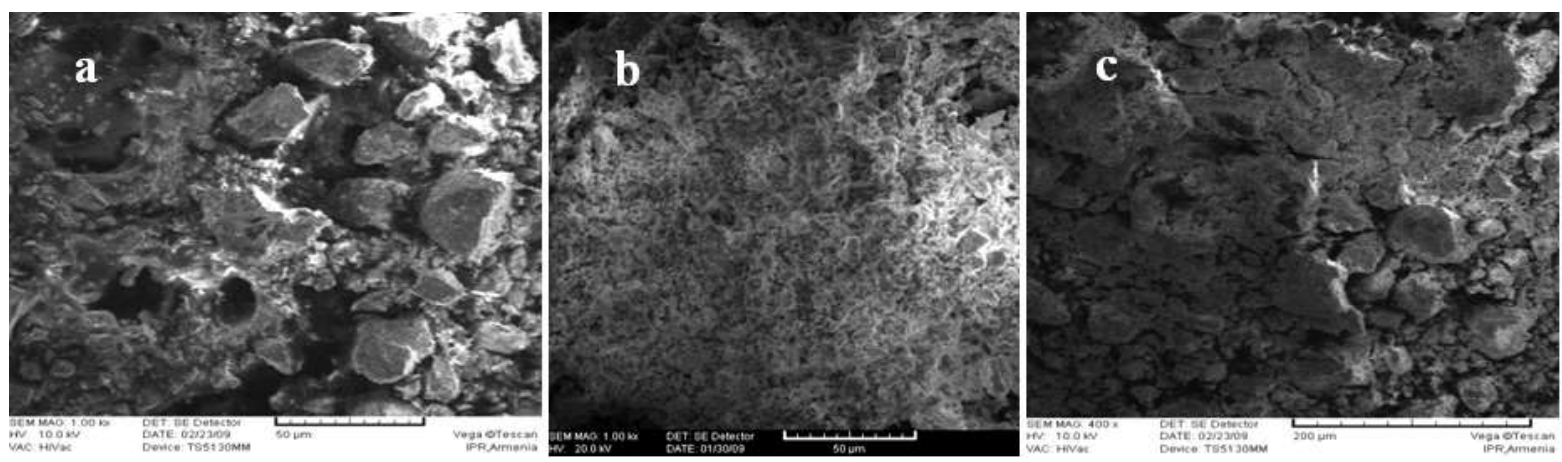

Fig. 1. The damp slag/chromite ratio: $a-0,5: 1 ; b-1: 1 ; c-2: 1$ 
Although, compared with the first ratio, here, the quantities of $\mathrm{Si}$ and $\mathrm{Cr}$ are a bit smaller, it is advantageous from the viewpoint of the structure.

The next figure introduces the dump slag/chromite ratio 2:1 (Fig. 1c). The alloy is less uniform here. In some places, rather large granules are observed. The alloy is externally less complete and has a porous structure. The degree of metal extraction here is $90 \%$. According to the data of the chemical analysis, the composition of the alloy is as follows: $\mathrm{Fe}-53 \%, \mathrm{Si}-27 \%$, and $\mathrm{Cr}-20 \%$.

The dump slag/chromite ratio 3:1 is introduced in Fig. 2a. Here, the alloy is less uniform. In some places, big granules are more, and the obtained alloy has a rather porous structure externally. The degree of metal extraction here is $91 \%$.

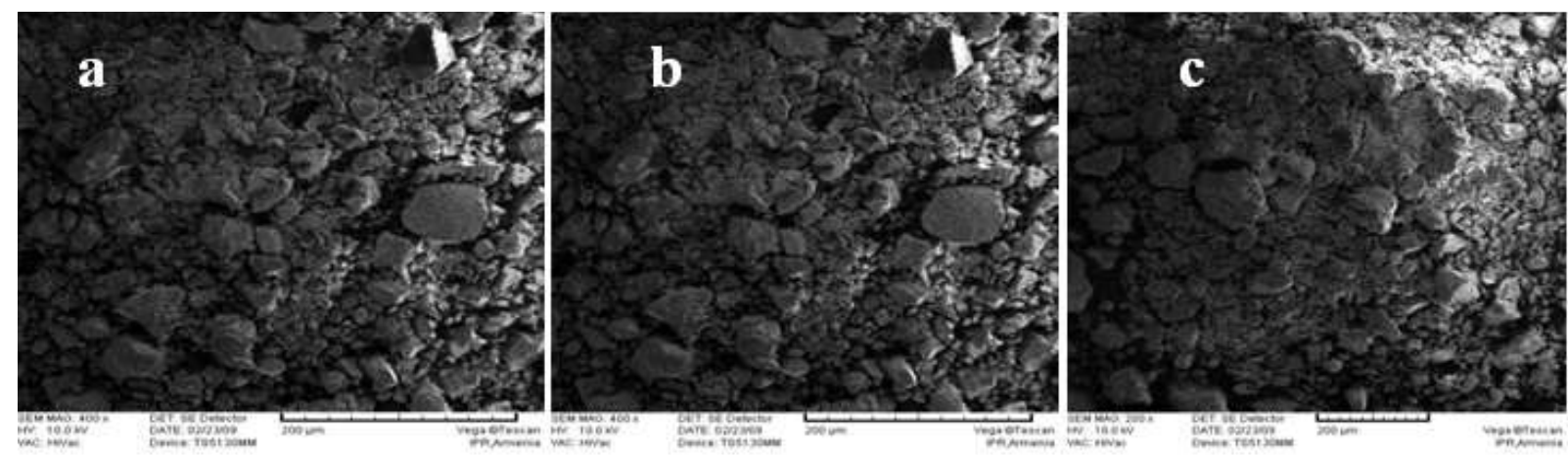

Fig. 2. The damp slag/chromite ratio: $a-3: 1 ; b-4: 1 ; c-5: 1$

According to the data of the chemical analysis, the composition of the alloy is as follows: $\mathrm{Fe}-$ $67 \%, \mathrm{Si}-23 \%$, and $\mathrm{Cr}-10 \%$.

The dump slag/chromite ratio 4:1 is introduced in Fig. 2b. In this case, the alloy is not uniform and the obtained alloy has a more porous structure externally. The degree of metal extraction here is also $91 \%$. According to the data of the chemical analysis, the composition of the alloy is as follows: $\mathrm{Fe}$ $-70 \%, \mathrm{Si}-21 \%$, and $\mathrm{Cr}-9 \%$.

The dump slag/chromite ratio 5:1 is introduced in Fig. 2c. As it is seen from the picture, the alloy is not homogeneous at all. Only big granules can be observed in the picture. The obtained alloy has a rather porous structure externally. The degree of metal extraction here is also the same $-8 \%$. According to the data of the chemical analysis, the composition of the alloy is as follows: $\mathrm{Fe}-72 \%, \mathrm{Si}$ $-20 \%$, and $\mathrm{Cr}-8 \%$.

Thus, the increase in the amount of iron, and, at the same time, the decrease in the amounts of silicium and chrome in the alloy lead to the deterioration of not only the ferrosilicochrome structure, but also the alloy quality. In all cases, the best results are obtained in the case of dump slag/chromite ratio $1: 1$, when an alloy of a microdisperse structure and high strength with rather a large outcome of metal is obtained.

In the next part of experiments, the tail slag was replaced by $\mathrm{Fe}_{2} \mathrm{O}_{3}$, which led to an increase in the yield of metallic phase. Particularly, at the 1:1 molar ratio this yield increases from 62 to $80 \%$. However larger amounts of Fe negatively influenced the alloy quality (a porous and ductile alloy was formed).

Experiments were also performed to raise the $\mathrm{Si}$ amount (in the form of $\mathrm{SiO}_{2}$ ). The best result was obtained at the $6,85 \%$ content of $\mathrm{SiO}_{2}$ in the charge. In this case, a 36,5\% content of $\mathrm{Si}$ was registered in the metallic phase. The further increase in the $\mathrm{SiO}_{2}$ amount in the initial mixture leads to impairment of the quality of the metallic phase.

The yield of the metallic phase, depending on the amounts of $\mathrm{CaO}, \mathrm{Fe}-\mathrm{Si}$ and $\mathrm{NaNO}_{3}$ was also studied. Optimal conditions for obtaining ferrosilicochromium were found to be: chromite/tail slag ratio of 1:1; contents of $\mathrm{Fe}-\mathrm{Si}-25 \% ; \mathrm{Al}-5 \%, \mathrm{CaO}-30 \%$, and a $30 \%$ excess of $\mathrm{NaNO}_{3}$ in the charge mass. Under these conditions, the composition of the obtained alloy was as follows: $35.1 \% \mathrm{Fe}$, $36.35 \% \mathrm{Si}$ and $28.53 \% \mathrm{Cr}$, and the extraction level of the metal was $98.4 \%$. Fig. $3 a, b$ illustrates the XRD pattern and the microstructure of the final product.

As silicon is equally well dissolved both in iron and chromium forming $(\mathrm{Fe}, \mathrm{Cr}) \mathrm{Si}$ and $(\mathrm{Fe}, \mathrm{Cr}) \mathrm{Si}_{2}$, which are charachterized by similar diffraction peaks, one can assert with confidence that ferrosilicachromium alloy has been obtained. 

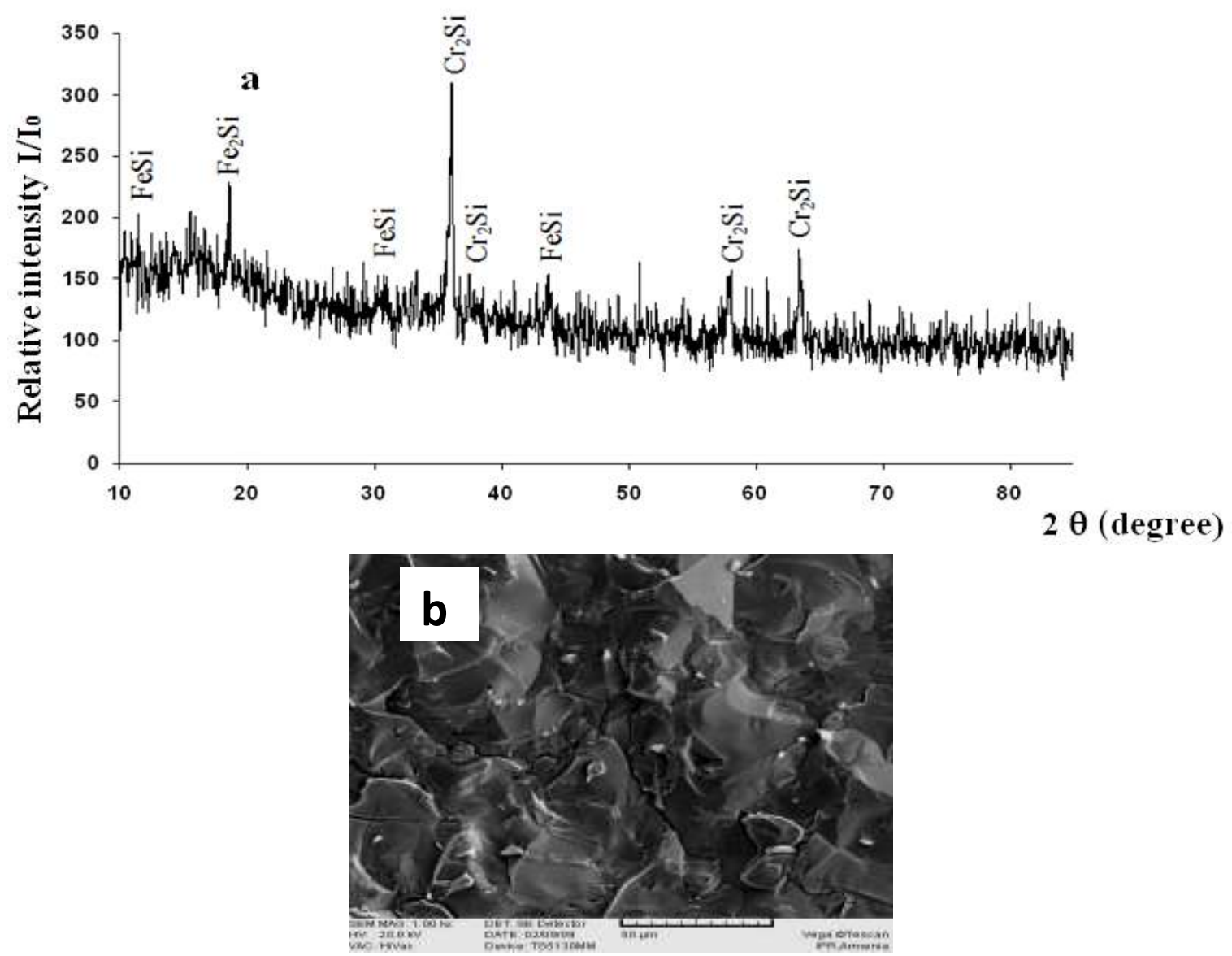

Fig.3. The XRD pattern (a) and the magnified 3000 times microstructure (b) of the combustion product

The aspects of mechanism of FeSiCr alloy obtaining process were developed (Fig.4).

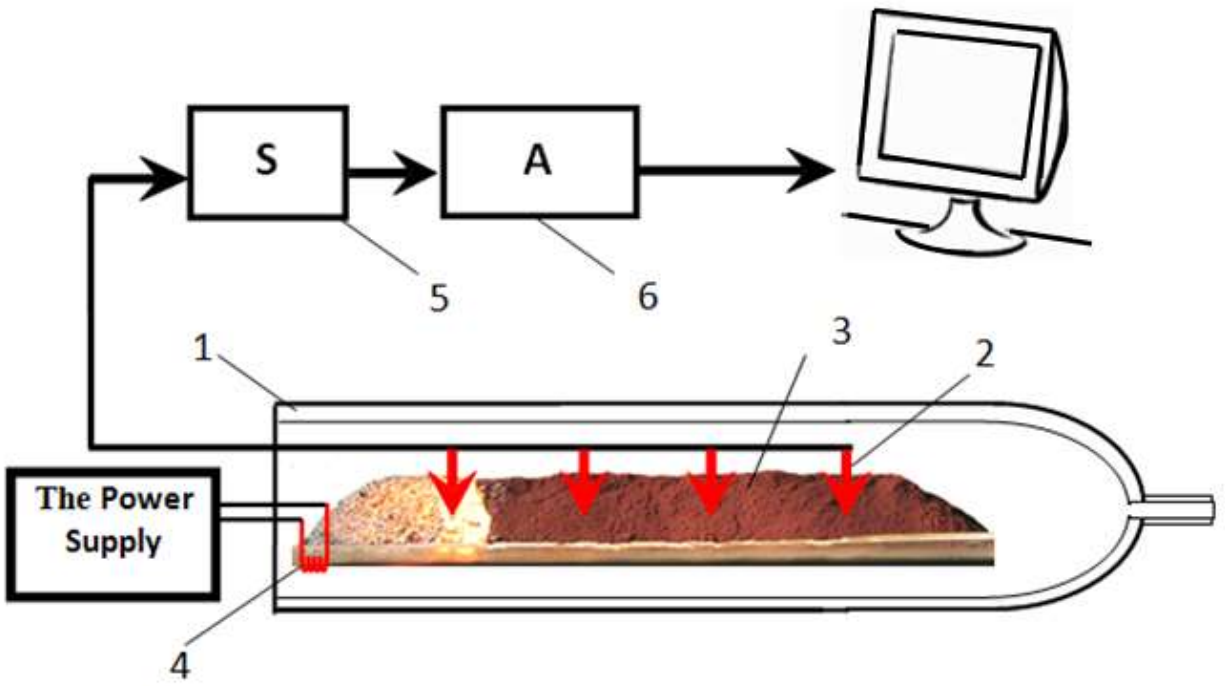

Fig. 4. The Laboratory SHS reactor

1 -Quartz boat, 2 - Thermocouples, 3 - Initial mix,

4 - Heat thread, 5 - The signal accelerator, 6 - Analogue

By the analog-to-digital converter Ni-USB-610M, and the LabView software package, some theoretical problems concerning the silicathermical reduction of the chromite concentrate and wastes by SHS method were studied. 
The experiments were carried out in the following way [20-22]: a certain amount of the charge was placed in a quartz boat-type crucible in a compressed or a free state, in which at a certain distance from each other $(20 \mathrm{~mm}) 4 \mathrm{~W}$-Re thermocouples (2) were recessed. The temperature was determined by the thermoelectric principle. The thermocouples were placed in the charge so that the heat loss of the environment should be minimal, which is important for the accurate temperature measurement.

For registration and processing of signals obtained by means of thermocouples, they are connected to the signal amplifiers (5), after which the amplified signals are connected to the input of the Ni-USB-610M analog-digital converter, the signals obtained at the output of the latter, were entered into a computer (7) and processed using the Lab View software.

The experiments were carried out as follows: to the beginning of the charge placed in quartz boattype crucible the $(\mathrm{Fe}+\mathrm{C})$ initiator is added and with hot wire made of $\mathrm{W}$, the self-propagating hightemperature synthesis was initiated and the wave dispersion at a constant rate was spread, passing successively through the four thermocouples along the entire length of the charge. At the end of the process, the boat-type crucible was cooled, and the metallic phase was allocated out of the charge. The occurrence of temperature profiles, depending on the amount of the reducing agent was investigated (Fig. 5).
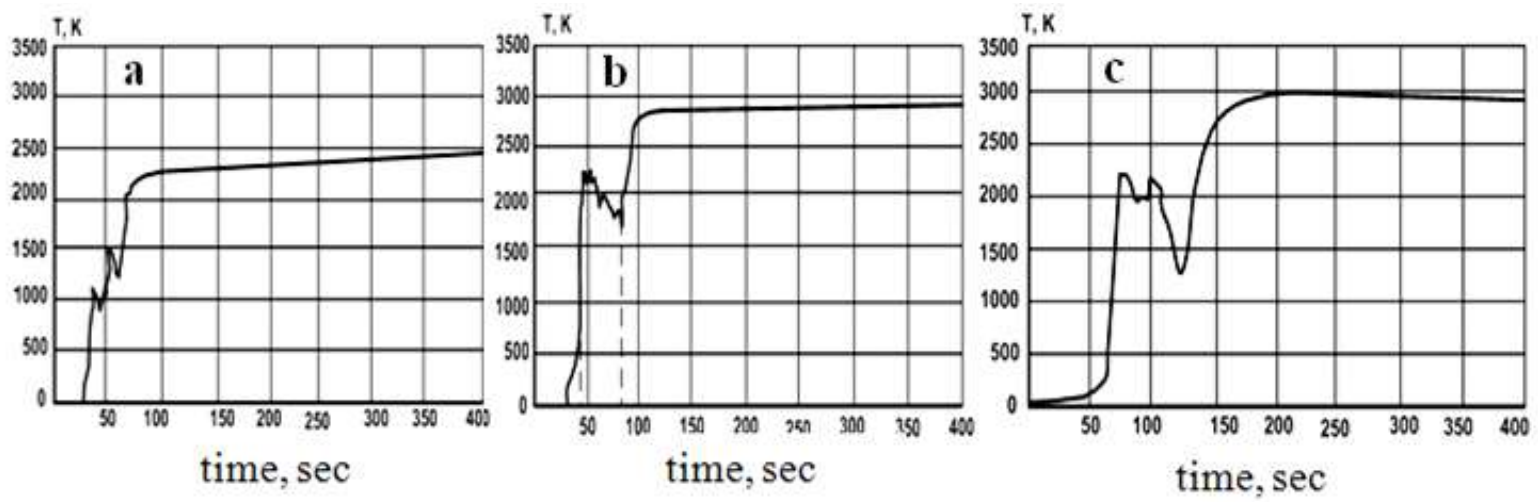

Fig. 5. Temperature profiles of the FeSiCr production, depending on the amount of the reducing agent: a) the theoretically necessary amount; b) 20\% and c) 60\% excess amounts

By the type of temperature profiles, it is evident that the alloy synthesis is carried out in a fixed rate. However, the multiple endothermic and exothermic effects associated with the synthesis of the alloy with gradual reduction and destruction of chromites in the range of $50 \ldots .150 \mathrm{sec}$. is observed after the start of reaction. The thermal effects are especially amplified with an increase in the reducing agent amounts. In the latter case, at the maximum amount of the reducing agent, and a duration of $100 \ldots .150 \mathrm{sec}$. on the curve, the strong endothermic effect is likely associated with the entire recovery of iron oxide and with the final destruction of the chrome-spinelide crystal lattice. In all cases, first iron is reduced, thus not violating the integrity of the crystal lattice of the chrome-spinelide. After a complete reduction, the chromium reduction begins, thus, the reduced iron contributes to the extraction of chromium oxide. The extraction of silicon is derived from the free $\mathrm{SiO}_{2}$, contained in the charge - along with the chromium oxide extraction. Then the final reduction of chromium and silicon oxides and the synthesis of $\mathrm{FeCrSi}$ take place, after which the temperature of the mixture increases, reaching a maximum - up to $3000 \mathrm{~K}$.

Based on the temperature profiles of the reduction process, the values of quantities will be defined, some problems connected with the SHS mechanism of the process for obtaining ferroussilicium-chrome will be elucidated.

The maximum combustion temperature (Tc), and the linear combustion velocity (Uv) were defined graphically [23-25].

As can be seen from the curves (Fig.6), the increase in the amount of the reducing agent leads to a higher combustion temperature from 2500 to $3000 \mathrm{~K}$. The velocity of the combustion front (Uv) propagation increases, too. This phenomenon is explained by the fact that the emission heat in the process increases and the thermal conductivity of the synthesized alloy also increases. Studies have shown that the synthesis parameters have a significant impact on the dispersion degree of the initial feedstock. As shown in Figure 7, the dispersion increasing from 120 to 20 microns significantly increases the values of both Tc and Uv. Thus, obtaining temperature profiles allows to determine the dependence of the combustion temperature $(\mathrm{Tc})$ and the velocity of the combustion front propagation (Uv) on the amount of the reducing agent contained in the charge and the degree of dispersion. Simultaneously, the resulting form of profiles 
allows to clarify some issues of the reduction mechanisms for the ferrosilicochrome reduction, applying the chromites recovery method by ferrosilicone.

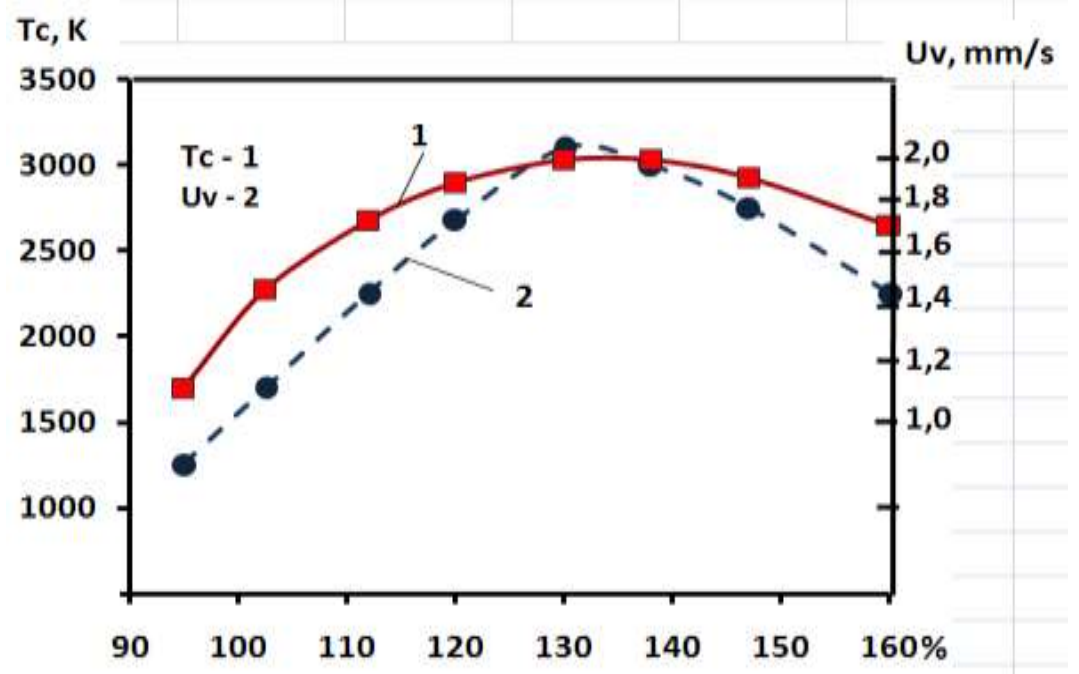

Fig.6. The dependence of the combustion temperature (Tc), and the velocity of propagation of the combustion front $(U v)$ on the amount of the reducing agent contained in the charge

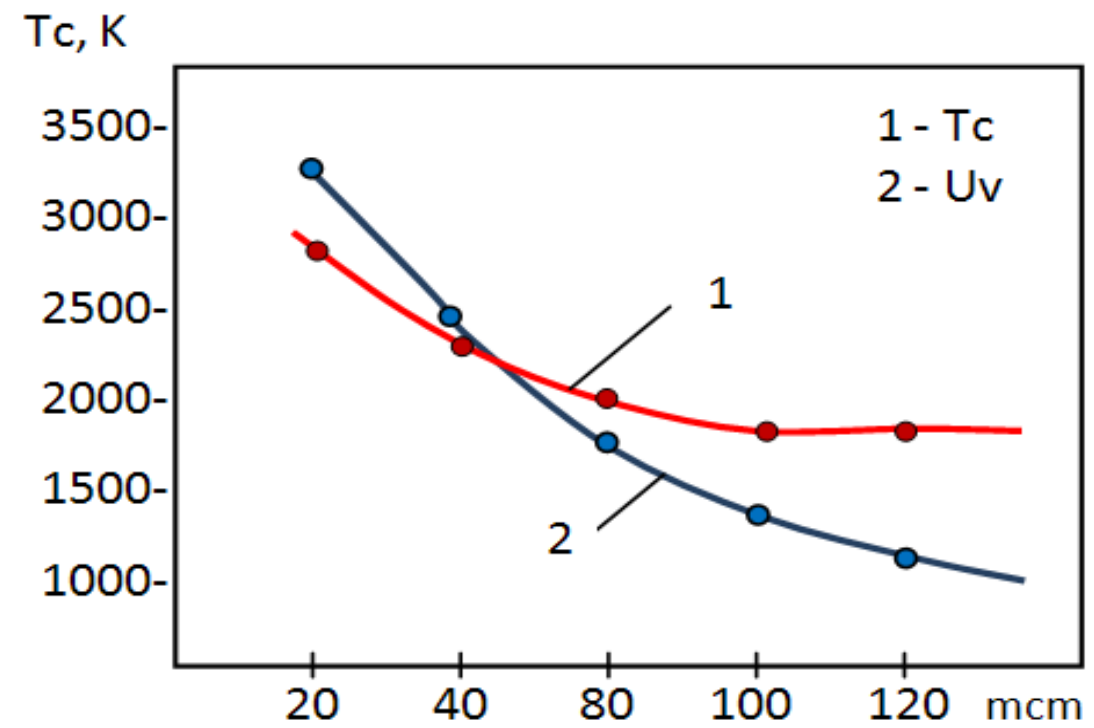

Fig.7. The Dependence of the combustion temperature (Tc) and the velocity of propagation of the combustion front $(U v)$ on the degree of dispersion of the charge

The solution of these issues can help to solve a number of technological problems concerning the production of ferrosilicochrome. By controlling the synthesis process, it is possible to obtain substances of a given composition, structure and characteristics. Thus, experimental investigations have demonstrated the possibility of producing a valuable ferrosilicachromium alloy by combined silicothermic reduction of Tapasar's chromites and tail slags of the Alaverdi copper smelting factory with the metal yield of $98,4 \%$.

4. Conclusions. It is envisaged to perform experimental investigations of the Tapasar chromite concentrate and copper-smeltery waste products by the simultaneous silicothermic reduction method for obtaining ferrous-silicium-chrome. The dependence of the metal's total output on the waste product-chromite relation, on the batch mixture reducing agent, the quantity of $\mathrm{NaNO}_{3}$ and $\mathrm{CaO}$ has been studied. The optimum SHS conditions for providing the maximum exit of an alloy are selected.

The parameters of burning process of (temperature and speed) has been defined.

The structurization problems of the obtained results have been studied by the microscopic method under the conditions of various ratios of waste products - chromites.

The investigation of ferrous-silicium-chrome microstructure has been performed by the scanning microscopic and X-ray-phase analysis method. 
In terms of theoretical and experimental results of investigations, the Tapasar chromite concentrate and waste products from copper-smeltery together with the siliciothermy reduction process by the out-of-furnace silicotermic reduction method has been performed, the productive technology of obtaining ferrous-silicium-chrome additives will be developed and the technologicaleconomic substantiation will be carried out.

The developed technology will not require huge expenses, and it can be easily implemented in "Armenian Molybdenum Production" works functioning in Yerevan. Simultaneously the results obtained will create the necessary prerequisites for founding non-traditional productions based on energy and ore saving technologies in Armenia which will allow to solve a number of ecological problems.

Acknowledgements. This work was financially supported by the RA MES State Committee of Science and Belarusian Republican Foundation for Fundamental Research $(R B)$ in the frames of the joint research projects SCS and BRFFR - accordingly (13-РБ049).

\section{REFERENCES}

1. Aloyan P.G. Material composition and metalliferous of chromite ores of Tapasar deposit - [Yerevan], JSC "Mining - Metallurgical Institute of Sevan ophiolitic stripes", 2005, 32 p.

2. Martirosyan V.A. Processing of metal ores of Armenia by chlorination: Monograph. [Germany] Lap Lambert Academic Publishing, ISBN: 978-3-659-78413-2 (2015) 200 p.

3. Martirosyan V.A., Manukyan N.V. Investigation of the chlorination mechanism of metal oxides by chlorine. Journal of Materials Processing Technology. [Ireland]142, 2003, pp. 145-151.

4. Martirosyan V.A. Chemical-Metallurgical Processes of Reprocessing the ores of Armenia: Monograph [Germany], Lap Lambert Academic Publishing, ISBN: 978-3-659-76299-4, 2015, 154 p.

5. Martirosyan V., Hakobyan N., Sasuntsyan M. Studies on enrichment processes of Sevan Tapasar deposit chromites, SEUA Annual Conference - Collection of materials [Yerevan] 2, 2006, pp. 610-613.

6. Patent No 2275A. An enrichment method of chromite ore, Martirosyan V.H., Sasuntsyan M.E., Ghukasyan Zh.H., Hakobyan N.N., Ayvazyan A.A. (27.04 2009) [in Armenian].

7. Martirosyan V., Torosyan G., Sasuntsyan M., Torosyan N. Obtaining of ferrosilicochromium alloy by silicothermic reduction of the Tapasar chromites and slags of copper casting factories, Meridian ingineresc, ISSN 1683-853x, 2012, 2, pp. 68-72.

8. Martirosyan V., Torosyan G., Sasuntsyan M., Torosyan N. Chromium obtaining from Armenian chromite concentrate by SHS in the presence of chloride, Meridian ingineresc, ISSN 1683-853x, 2012, 2, pp. 33-37.

9. Pliner J.L., Ignatenko G.F., Lappo C.I. Chromium Metallurgy [M], Metallurgiya Press, 1965, 2012, 362 p.

10. Sally A., Brendz E. Chrome / Trans. from English. V.A. Alekseeva; ed. by V.A. Bogoliubov [M], Metallurgiya Press, 1971, 359 p.

11. Sokolov I.P., Chekmarev A.M., Seleznev V.P., Kozyrev A.V. Peculiarities of solid-state metallothermic reactions, Izv. AN SSSR. Metaly 1990, 2, $17 \mathrm{p}$.

12. Vilnyansky Y.E., Martirosian V.A. Selective chlorination of Sevan chromite ores Industry of Armenia [Yerevan] 1972, 9, pp. 48-50.

13. Dubrovin A.S. Prospects of development of aluminothermic production of ferroalloys $[\mathrm{M}]$, Metallurgy Press, 1993, $715 \mathrm{p}$.

14. Martirosyan V., Sasuntsyan M. Complex mineralogical investigation of copper and molybdenum slags in the acting metallurgical plants of Armenia. Yale Journal of Science and Education.- Yale University Press, 2016, 10, pp. 413-420.

15. Philipova N.A. Phase analysis of ores and products of their processing, [M] Chemistry Press, 1975, $280 \mathrm{p}$.

16. Durrer R., Folkert G. Metallurgy of ferroalloys, [M], Metallurgy Press, 1976, 47 p.

17. Revenko A.G. X-ray spectral fluorescence analysis of natural materials. [Novosibirsk] Nauka Press, 1994, 264 p.

18. Mazalov L.N. X-ray spectra and chemical relation [Novosibirsk] Nauka Press, 1982, 111 p.

19. Pichugin V.F., Yanovskiy V.P., Morosova N.S., Yermolovich I.M. 10th International Conference on Modification of materials with Particle Beams and Plasma Flows, Proceedings [Tomsk], 2010, pp. 672 -675.

20. Martirosyan V.A., Sasuntsyan M.E. Study of the mechanism of iron monosilicide obtained from industrial wastes, International scientific review, [Boston USA], 2016, 14, pp. 40-42.

21. Merzhanov A.G., Yukhvid V.I., Borovinskaya I. P. Proceedings of AS USSR, 1980, 255, 120 p.

22. Yukhvid V. I. Self-propagating high-temperature synthesis: Theory and practice, Under Edition of A.E. Sichev, [Chernogolovka], Territory Press, 2001, 252 p.

23. Zenin A.A., Nersisyan G.A. Thermal structure of the SHS wave, mechanisms and macrokinetics of hightemperature interaction of elements in the system Ti - Si and Zn - Si. Preprint, [Chernogolovka], IOCHF, 1980, 42p.

24. Samsonov G.V., Chistyakov Yu.D. Metallothermic methods in chemistry and metallurgy, Uspekhi Khimii, 1996, 25, $30 \mathrm{p}$.

25. Pashinkin A.S., Spivak M.M., Malkova A.S. Application of partial pressure diagrams in metallurgy, Moscow, Metallurgy Press, 1984, 160p. 